\title{
An Approach to Adaptivity and Collaboration Support in a Web-Based Learning Environment
}

\author{
doi:10.3991/ijet.v4s3.1071 \\ Martina Holenko Dlab and Nataša Hoić-Božić \\ University of Rijeka, Rijeka, Croatia
}

\begin{abstract}
The development of Web 2.0 and social software applications was not initially aimed for education, but its influence in this field, especially in e-learning, is recently recognized as positive. New approach to e-learning inspired by these technologies is called e-learning 2.0 . It emphasizes social learning using different tools available on the web rather then integrated systems like LMSs. This paper describes framework for further development of adaptive LMS according to constructivist theory of learning, advantages of Web 2.0 applications and characteristics of elearning 2.0.
\end{abstract}

Index Terms - collaborative learning, e-learning 2.0, personal learning environments, Web 2.0.

\section{INTRODUCTION}

New approaches in development of the web-based learning environments are associated with adoption of student-centred teaching model based on the constructivist theory of learning, and since recently, with development of Web 2.0 and social software.

While working with the traditional educational hypermedia systems all students receive access to the same learning material and set of tools. This so-called "one size fits all" approach offers equal services to all students, without adapting it to their knowledge, goals, communication skills, affinities and interests [1]. Adaptive hypermedia field deals with this problem, so adaptive hypermedia systems (AHS) beside standard features enable the use of adaptive content and navigation in the learning process.

Numerous adaptive hypermedia systems reflect "teaching" perspective where the primary goal is delivering course materials. In order to raise students' motivation, new approaches are emphasizing the collaborative learning and aim at so-called "learning" perspective [2]. Collaborative learning is based on the constructivist theory which assumes that students learn from each other during learning activities and that they actively participate in construction of knowledge. The implementation of tools that enable and foster communication and collaboration between students is therefore necessary and in numerous cases it is realized through a learning management system (LMS).

Enriching collaborative support with adaptivity is a new opportunity for AHS. The main goal of using adaptive techniques in context of web-based educational systems that support collaboration is not to take away initiative from students, but to support them in achieving productive collaboration. Intelligent technologies are used in order to extend the abilities of collaboration tools like chat or discussion forums provided by various LMSs, to compensate the students' inability to create personal mental models of their colleagues' learning characteristics, and to help them in achieving social cohesion. There are efforts to model students' collaboration activities, especially while working in groups, and to guide and support them before, during and after delivering learning materials [2].

Related work includes approaches for combining adaptivity with advances in domain of social software through adaptive social navigation support [3], social browsing, and social tagging [4]. For example, in system WHURDLE 2.0 [5], adaptation of content is combined with social and collaborative learning tools from LMSs that provide social aspects of e-learning (e.g. Moodle). Some work in the field includes architecture for integration of distributed learner information through a Web services, tag-based [6] or agent-based user models [7].

This paper describes our work in progress for further development of adaptive learning management system called AHyCo towards " 2.0 " version in order to facilitate collaboration between students according to constructivist theory of learning, advantages of Web 2.0 applications and characteristics of e-learning 2.0.

\section{E-LEARNING 2.0 AND PERSONAL LERANING ENVIRONMENTS}

Teachers are already using tools like forums, wikis, whiteboards or video conferences to support different activities involved in the learning process and to foster collaboration between participants of e-learning programs and courses. However, numerous novel Web 2.0 applications, especially social software, enable learners to gain knowledge in a new, more creative and more interesting way.

Social software is a group of tools that supports social networking and individual publishing (e.g. blogs, social bookmarking services, applications for sharing multimedia content, etc.). The development of Web 2.0 and social software was not initially aimed for education, but its influence in this field, especially in e-learning, is present and recognized as positive. Active participation, expressing creativity and sharing ideas in a personalized, flexible and open learning environment are characteristics required for accomplishing learning objectives and raising educational processes on higher level [8].

To stress out the changes in learning processes induced by Web 2.0 and social software, a new approach to e-learning is called e-learning 2.0 [8]. E-learning 2.0 places students in the centre of learning process. They are learning more through informal then formal ways of learning and become active participants through sharing ideas 
and knowledge with their peers, joining the communities of practice [9].

Connections play significant role in learning so the term connectivism is used to define principles of this new form of learning [10]. Connectivism, as learning theory, emphasizes skills and tasks needed for success in a digital age. Among them are potential to distinguish relevant from unimportant information (deciding what to learn), ability to perceive connections between different fields, concepts and ideas (in order to combine different resources while learning), as well as to maintain connections with people.

The novel e-learning 2.0 approach is based on personal learning environments (PLE). According to [9], personal learning environment is a personal space in which students organize resources that have the potential to support their learning. It is not a software application but approach to using technologies for learning [11].

Personal learning environments are based on the idea that learning process takes place in different contexts and situations [11] so they are, comparing to LMSs, decentralized. PLE is a distributed environment that consists of network of people, resources and services. Choosing resources and peers depending on their needs, interests and goals, students are creating their own learning environments so, according to [9], there is no need for creating virtual classroom any more. Instead of integrating all functions within a system, new approaches recommend making available separate tools to support different needs of students. As argued in [12], the reason for this decentralized approach is inability to structure or pre-determine the students' activities in a learning process.

New trend also allow students to use web application mash-ups as part of personal learning environment. Mashup approach brings combination of functionalities from multiple Web 2.0 applications in order to ensure unified user experience. This kind of integration and cooperation between single applications allow students to define a set of tools they want to use and visualize them in a grid layout [13].

\section{ENRICHING PERSONAL LEARNING ENVIRONMENT USING RECOMMENDER MODULE OF AHYCO SYSTEM}

AHyCo (Adaptive Hypermedia Courseware) [14] is a web-based adaptive learning management system that supports interaction between students and content by using adaptive hypermedia and online tests. AHyCo consists of a domain model, a student model, an adaptive model and a collaborative model. Different collaborative functionalities like automatic grouping of students based on various criteria, asynchronous communication tool (forum) and file sharing options are already introduced into the collaborative module of AHyCo [15].

Further development of the system with intention to adaptively support collaboration process assumes accessibility of different collaboration tools. Although the implementation of additional tools like wiki, internal messaging system, synchronous whiteboard and chat as a part of LMS as a closed system was planed, a new approach that tends to openness incited the development of the " 2.0 " version of the system that will enable students communication and collaboration using applications available on the web.

\section{A. Combining Adaptive LMS with Web 2.0 Applications to PLE}

Creating personal learning environment in a sense of choosing a set of Web 2.0 applications or services to facilitate own learning process is not a simple task for students. Opposed to context where teacher organizes activities during the e-learning course, students need to take over initiative, responsibility and be more independent in choosing tools.

It is questionable whether the student will make the right choice and find tools that would enable him/her achieving learning objectives. Additionally, students with no prior experience may find it difficult and time consuming to learn how to use certain application, as well as to recognize its advantages or disadvantages. On the other hand, Web 2.0 approach empowers students with variety of different resources which can be used for independent work and/or collaboration and therefore become the part of their personal learning environments.

Due to above mentioned, recommender module of AHyCo system will be used for choosing appropriate learning tools (Web 2.0 applications or services) that will be suggested to individual student or to a group of students, based on information in student and collaborative modules. Instead of integrating different tools within the system, students will be provided with recommendations for using tools available on the web. To personalize the process of expanding learning environment from LMS to Web 2.0, combination of strategies of adaptive hypermedia and recommender system will be used.

This approach does not tend to confront LMS and personal learning environments, but rather to take advantages of both in order to provide new pedagogical opportunities for students. The use of LMS is not considered studentcentered, but course-centered, however it supports management of learning content and learning activities usually throughout simple and user-friendly interface. In case of adaptive LMSs, the ability to personalize learning process and to adapt to students' preferences and needs emphasizes pedagogical side of the system more then its administrative purpose. Thus, the use of these kinds of learning environments, especially within the context of e-learning in formal education, can not be neglected.

\section{B. Proposal for the Recommender Module}

As described above, the purpose of implementation of the recommender module in AHyCo system is to facilitate the process of choosing Web 2.0 applications which will together with AHyCo LMS become part of student's personal learning environment. Primary goal of this module is to enable students to take part in learning activities and achieve productive collaboration with their peers using chosen tools.

It is planed for the teacher to make initial list of tools according to expected learning outcomes, course contents and desired activities. It will be possible that teacher broaden this list with similar tools according to students' suggestions. To make the usage easier and more efficient, teacher will provide students with short description and instructions for every suggested tool.

When student start to use AHyCo's recommender module, there will be no data containing his/her characteristics and preferences. In order to address this so-called "cold-start" problem of recommendation systems [16], 
some information will be collected from students on the beginning of the course. By answering a few questions related to their preferences and prior experience with Web 2.0 tools, students should provide module with information sufficient to begin receiving personalized recommendations. However, this questionnaire should not be burdensome for student in order to avoid the chance that he/she gives up.

To provide students with accurate recommendations, the use of hybrid recommendation techniques is planed. Hybrid techniques combine recommendations based on social/community driven information (collaborative filtering) with ones based on individual information (contentbased techniques) [17]. According to that, the module will recommend tools that were used by other students with similar personal characteristics. Recommendations will be also based on data driven from student's behaviour and feedback on experiences in using recommended tools (recommended tools will be similar to the ones that he/she preferred in the past). During the recommendation process, students' knowledge level will also be taken in consideration. For example, regardless to the same preferences or interest that students may have, the module could recommend the use of simpler tool to students with low knowledge level, and more specific applications to advanced learners.

Besides personalization, sharing and two-way communication will be provided by allowing students to comment and tag suggested tools, or to invite their colleagues to use a particular tool.

In our future work we will examine various criteria for recommendations together with user modelling techniques in order to provide more information for recommendation rules. With intention for better support to process of collaboration establishment our future plans also include development of new algorithms for grouping and peer matching based on the usage of Web 2.0 tools.

\section{CONCLUSIONS}

Traditional educational hypermedia systems provide access to the same learning material and a set of tools to all students. Learning environments based on Web 2.0 characteristics promote personalization and students expect service tailored by their preferences, interests and needs.

Purpose of implementation of new recommender module to AHyCo system is to provide students with Web 2.0 tools or services which they can use on their own or in collaboration with others. By recommending applications available on the web, instead of integrating them within the system, AHyCo will enable students to try different applications and find ones that suite them best. In other words, students will get chance to enrich their personal learning environment.

Although e-learning 2.0 assumes autonomous students, adaptive support is planed. Its intention is not to take away students' initiative in choosing tools, joining certain community of practice or social network, but to guide them in order to ensure productive collaboration with colleagues and achieving learning objectives.

Key challenges of our further researches are different recommendation criteria and user modelling that would make possible adaptation based on students' activities using social software and other Web 2.0 applications.

\section{REFERENCES}

[1] P. Brusilovsky, "Adaptive and Intelligent Technologies for Webbased Education". In: Special Issue on Intelligent Systems and Teleteaching, C. Rollinger and C. Peylo (Eds.): Künstliche Intelligenz, 4, 1999.

[2] A. Paramythis, J. R. Mühlbacher, "Towards New Approaches in Adaptive Support for Collaborative E-Learning". Proceedings of the Eleventh IASTED International Conference on Computers and Advanced Technology in Education (CATE 2008), 2008, Crete, Greece

[3] R. Farzan, P. Brusilovsky, "Social Navigation Support in a Course Recommendation System". In: Proceedings of 4th International Conference on Adaptive Hypermedia and Adaptive Web-based Systems, Dublin, 2006, pp. 91-100

[4] S. Bateman., R. Farzan, P. Brusilovsky, G. McCalla, "OATS: The Open Annotation and Tagging System". In: Proceedings of Third Annual International Scientific Conference of the Learning Object Repository Research Network (I2LOR-06), Montreal, Canada, 2006.

[5] M. Meccawy, P. Blanchfield, H. Ashman, T. Brailsford, A. Moore, "WHURLE 2.0: Adaptive Learning Meets Web 2.0", P. Dillenbourg and M. Specht (Eds.): EC-TEL 2008, pp. 274-279,

[6] F. Carmagnola et al., "Towards a Tag-Based User Model: How Can User Model Benefit from Tags?" In UM '07: Proceedings of the 11th international conference on User Modelling, 2007. pp. 445-449, Berlin, Heidelberg. Springer-Verlag.

[7] A. Lorenz, "Agent-Based Ubiquitous User Modeling". In: User Modeling, L. Ardissono, P. Brna, A. Mitrovic (Eds.): UM 2005, LNAI 3538, pp. 512 - 514, 2005. Berlin Heidelberg SpringerVerlag

[8] P. Anderson, "What is Web 2.0? Ideas, technologies and implications for education", JISC Technology and Standards Watch, 2007

[9] A. Bartolomé, "Web 2.0 and New Learning paradigm", eLearning Papers, no. 8, 2008.

[10] G. Siemens, "Connectivism: A Learning Theory for the Digital Age". International Journal of Instructional Technology \& Distance Learning, Vol. 2 No. 1, 2005.

[11] G. Attwell, "Personal Learning Environments - the future of eLearning?" eLearning Papers Vol 2, No. 1, 2007. pp. 1-8

[12] C. Dalsgaard, "Social software: E-learning beyond learning management systems", European Journal of Open and Distance Learning (EURODL), No. 2, 2006.

[13] F. Mödritscher, G. Neumann, V.M. García-Barrios, F. Wild, "A Web Application Mashup Approach for eLearning”. Proceedings of the OpenACS and .LRN Conference, 2008. pp. 105-110

[14] N. Hoić-Božić, V. Mornar, “AHyCo: a Web-Based Adaptive Hypermedia Courseware System". CIT. Journal of computing and information technology. Vol. 13, No. 3, 2005. pp. 165-176 (doi:10.2498/cit.2005.03.01)

[15] N. Hoić-Božić, V. Mornar, I. Botički, "Introducing adaptivity and collaborative support into a Web-based LMS". Computing and informatics, Vol. 27, 28, 2008. pp. 639-659

[16] A. M. Rashid, G. Karypis, J. Riedl, "Learning preferences of new users in recommender systems: an information theoretic approach". SIGKDD Explor. Newsl. 10, 2, 2008. pp. 90-100

[17] H. Drachsler, H. G. Hummel, R. Koper, "Personal recommender systems for learners in lifelong learning networks: the requirements, techniques and model”. Int. J. Learn. Technol. 3, 4, 2008. pp. 404-423

\section{AUTHORS}

M. Holenko Dlab is an Assistant at the Department of Informatics, University of Rijeka, 51000 Rijeka, Croatia (e-mail: mholenko@inf.uniri.hr).

N. Hoić-Božić is an Associate Professor at the Department of Informatics, University of Rijeka, 51000 Rijeka, Croatia (e-mail: natasa.hoic@ri.t-com.hr).

This article was modified from a presentation at the International Conference of Interactive Computer Aided Learning ICL2009, September 2009 in Villach, Austria. Submitted 01 October 2009. Published as resubmitted by the authors on 2 November 2009 . 